\title{
Clinical and Laboratory Findings on Complication in Patients With Leptospirosis in Mazandaran Province, Iran
}

\author{
Narges Najafi ${ }^{1}$; Ali Reza Davoudi ${ }^{1,} ;$ Shahriar Alian ${ }^{1}$; Fatemeh Ahangarkani ${ }^{1}$; Elham Asghari ${ }^{1}$ \\ ${ }^{1}$ Antimicrobial Resistance Research Center, Department of Infectious Diseases, Mazandaran University of Medical Sciences, Sari, IR Iran \\ ${ }^{*}$ Corresponding author:Ali Reza Davoudi, Antimicrobial Resistance Research Center, Department of Infectious Diseases, Mazandaran University of Medical Sciences, Sari, IR Iran. Tel/ \\ Fax:+98-1142316319, E-mail: eiy_iran@yahoo.com
}

Received: October 21, 2014; Revised: May 8, 2015; Accepted: May 15, 2015

\begin{abstract}
Background: Leptospirosis has a high mortality rate in north of Iran.
Objectives: The current study aimed to assess the clinical and laboratory findings and their possible relationship with complications of leptospirosis.

PatientsandMethods:The current retrospective cross-sectional study, byreviewing hospital records, evaluated patients with leptospirosis hospitalized in Razi Hospital (the therapeutic center of infectious diseases in Qaemshahr city, in the North of Iran) from 2008 to 2012 . The diagnosis was confirmed by increasing the antibody titer in immunofluorescence assay(IFA) or microscopic agglutination test (MAT).

Results: Out of 634 patients, 61 subjects (9.62\%) had significant complications including: acute renal failure, alveolar hemorrhage, ARDS, clotting disorders, pancreatitis, gastrointestinal bleeding and intracranial bleeding; Age, jaundice, renal and pulmonary involvement (oliguria and anuria), hypotension, leukocytosis, thrombocytopenia, hyponatremia, elevated bilirubin, alanine aminotransferase (ALT), Creatine phosphokinase (CPK), Lactate dehydrogenase (LDH) and erythrocyte sedimentation rate (ESR) increased the risk of leptospirosis complication.

Conclusions: Renal involvement is one of the leading causes of death in such patients.
\end{abstract}

Keywords: Leptospirosis; Weil syndrome; Complication

\section{Backgrounds}

Leptospirosis is a zoonotic disease distributed worldwide. Leptospira spp. may enter the host through an abraded skin or intact mucous membranes (1). Although the organism mainly infects the kidneys and liver, any organ may get involved (2). This disease has a wide spectrum of clinical manifestations that varies from subtle infections to fulminant and fatal diseases. Leptospirosis in its own mild form may appear as a flu-like illness with headache and myalgia (3). Severe leptospirosis with jaundice, renal dysfunction and abnormal bleeding is known as Weil syndrome (4). Certain occupational groups are especially at high risk including farmers, veterinarians, sewer workers, and people who work at abattoirs and fisheries industry (5). Leptospirosis is diagnosed based on the separation of the organism or seroconversion with increasing antibody titer in microscopic agglutination test (MAT) (4). Symptoms such as jaundice, hypotension, tachypnea and decreased urine volume are the factors that may worsen the prognosis of the disease (6). Factors affecting the incidence of complications of this disease are studied in several re- searches and there are significant regional differences in this regard.

\section{Objectives}

The current study aimed to assess clinical and laboratory findings and their possible relationship with leptospirosis complication.

\section{Patients and Methods}

The current retrospective cross-sectional study was conducted on patients with leptospirosis hospitalized in Infectious Diseases ward in Razi Hospital, a teaching and referral center in Qaemshahr city in Mazandaran province, North of Iran, from 2008 to 2012. Census method was performed for sampling. The study was conducted by reviewing hospital records. The inclusion criterion was the clinical and epidemiological data suggestive of leptospirosis. Exclusion criterion was no serologic findings of leptospirosis. The study was approved by the ethics committee of Mazandaran University of Medical Sciences (code number:

Copyright (C) 2015, Infectious Diseases and Tropical Medicine Research Center. This is an open-access article distributed under the terms of the Creative Commons Attribution-NonCommercial 4.0 International License (http://creativecommons.org/licenses/by-nc/4.0/) which permits copy and redistribute the material just in noncommercial usages, provided the original work is properly cited. 
Najafi Net al.

8984, Date: October 13, 2010). Serum samples of patients with suspected leptospirosis were tested by immunofluorescence assay (IFA) method, if the test was negative, the patient's sample was taken again and the test was repeated by microscopic agglutination test (MAT) method. Any antibody titer greater than 1:800 was considered positive. Data were entered and analyzed, including descriptive statistics with median values. Statistical analysis was performed using the SPSS software version 13.0 (SPSS Inc. Chicago, IL, USA). The descriptive values below $5 \%$ (P value $<0.05$ ) were considered statistically significant.

\section{Results}

\subsection{Demographic Features, Clinical Characteris- tics and Risk Factors}

There were 634 patients among which $72.2 \%$ were male and $27.8 \%$ female. The mean age was $41.25 \pm 16.95$ years (range, 11-84). The mean age for females was $44.57 \pm 13.86$ years and for males $39.97 \pm 17.84$ years. The difference between these two groups was statistically significant $(P=0.002)$. The highest incidence of the disease was in the age range of 20 - 40 years and the lowest incidence was in below 20 . The majority of patients were farmers (76.5\%) and in other patients, there was a history of contact with contaminated water or rice farms in different ways. Almost half of the subjects had been admitted to the hospital within three days of onset of symptoms. This rate was $91.5 \%$ in the first week and reached to $98.4 \%$ in the second week. The average time from symptoms' onset to admission was $4.46 \pm 3.59$ days. There was no significant correlation between onset of symptoms and serology positive patients $(\mathrm{P}>0.05)$. The most common chief complaints of patients were fever (71.3\%), jaundice (6.5\%) and myalgia (6\%), respectively. The most common symptoms were fever (92.1\%), myalgia (79.8\%) and headache $(60.1 \%)$, respectively (Table 1$)$. The leukocytosis was observed in $41.8 \%$ of the patients and leukopenia in $15.2 \%$. Approximately $67 \%$ of the patients had platelets less than 150,000 . Also anemia was observed in $21.6 \%$ of the females and $28.2 \%$ of the males (WHO defined anemia: $\mathrm{Hb}<12 \mathrm{~g}$ / $\mathrm{dL}$ for females and $\mathrm{Hb}<14 \mathrm{~g} / \mathrm{dL}$ for males) (7). Hypernatremia and hyponatremia were observed in 32.5\% and 5.2\% of the patients, respectively. Also potassium level in $8.5 \%$ and $5.6 \%$ of the subjects were below and above the normal range, respectively. The prothrombin time (PT) test was abnormal (more than 12.5 seconds) in $32.1 \%$ of the subjects. Only $27.4 \%$ of the patients had normal alanine aminotransferase (ALT) (4 - $36 \mathrm{U} / \mathrm{L})$ and the rest were admitted with increased ALT. In 3.5\% of the subjects, ALT was more than 300 and in 1.9\% above 500. Also AST increased in $73.3 \%$. In $5.9 \%$ of the patients, aspartate aminotransferase (AST) was greater than 300 and in $2.3 \%$ above 500 . ALP levels were normal in $28.5 \%$ of the subjects (30-120 U/L). Nearly $40 \%$ of the patients had high total bilirubin. The mean total bilirubin was $4.87 \pm 0.37 \mathrm{mg} / \mathrm{dL}$ in which the lowest recorded amount was $0.1 \mathrm{mg} / \mathrm{dL}$ and the highest was $36 \mathrm{mg} / \mathrm{dL}$. The creatinine level increased to $22.1 \%$. Only $2 \%$ of the subjects had normal lactate dehydrogenase (LDH). Meanwhile $49.9 \%$ of the patients had a LDH greater than $500 \mathrm{U} / \mathrm{L}$ and 6.1\% were above $1000 \mathrm{U} / \mathrm{L}$. Also a creatine phosphokinase (CPK) level greater than normal was observed in $49.2 \%$. The highest and lowest levels of CPK were reported 10000 and $26 \mathrm{U} / \mathrm{L}$, respectively. Among these patients, $18 \%$ had a CPK more than $500 \mathrm{U} / \mathrm{L}$ and $6 \%$ higher $1000 \mathrm{U} / \mathrm{L}$. In $81.9 \%$ of the subjects ESR was higher than normal ( $\geq 15 \mathrm{~mm} / \mathrm{h}$ ). The maximum ESR was reported $130 \mathrm{~mm} / \mathrm{hr}$. In urine analysis, there was pyuria, hematuria and proteinuria, in $25.6 \%, 34.7 \%$, and $24.8 \%$ of the patients respectively. Chest Radiograph (CXR) was abnormal in $5.4 \%$ of the subjects which nearly $2 / 3$ of them had reticulonodular infiltration. Hepatomegaly and splenomegaly were reported trough abdominal ultrasound in $15.7 \%$ and $11.4 \%$ of the patients, respectively.

\subsection{Patients With and Without Complications}

Out of the 634 patients, 61 subjects (9.62\%) had significant complications including acute renal failure, alveolar hemorrhage, Acute Respiratory Distress Syndrome (ARDS), clotting disorders, pancreatitis, gastrointestinal bleeding and intracranial bleeding; 38 patients $(62.30 \%)$ were male and $23(37.70 \%)$ female. there was no statistical difference between male and female patients with and without complications $(\mathrm{P}=0.10)$. The mean age of the patients with complications was $45.54 \pm 16.83$ years; while in the other patients it was $40.82 \pm 16.93$ that indicated a significant difference between the two groups ( $\mathrm{P}=0.039$ ). The average time between onset of symptoms and facing with complicated and uncomplicated situations was 5.01 \pm 2.78 days versus $4.38 \pm 3$.64. There was no statistically difference between the two groups $(\mathrm{P}=0.18)$. The most common complaint of patients about side effects was fever (65.57\%), jaundice (14.75\%), weakness and lethargy (8.19\%), respectively. The most common symptoms were myalgia (88.52\%) and fever (86.88\%). Jaundice was more common in patients with complications with high significance $(\mathrm{P}$ $<0.0001)$. The mean systolic blood pressure in patients with and without complications was $113.45 \pm 18.77$ versus $112.46 \pm 14.15$, respectively $(\mathrm{P}=0.61$ ). The blood pressure was not associated with risk of disease complications $(\mathrm{RR} \approx 1)$. Approximately $20 \%$ of the patients with complications $(\mathrm{n}=12)$ and $7.73 \%$ of patients without complications $(\mathrm{n}=44)$ had CXR abnormalities that showed statistically a significant difference between the two groups ( $P$ $=0.003)$. Table 2 shows the mean of biochemical tests in the subjects with and without complications, separately. A rise of leukocyte and platelet counts and elevation of Cr, bilirubin, CPK, LDH and ESR and decrease of serum level of sodium and potassium, was significantly accompanied with an increased risk of complications. Of these 61 subjects, nine patients died and the cause of death for seven of them was severe kidney problems and two others died due to pulmonary involvement. 
Najafi $N$ et al.

Table 1. Clinical Findings of Patients With Leptospirosis ${ }^{\text {a }}$

\begin{tabular}{|c|c|c|c|c|}
\hline Clinical Feature & Total & Uncomplicated & Complicated & PValue \\
\hline Fever & $584(92.1)$ & $530(92.5)$ & $54(88.5)$ & 0.05 \\
\hline Myalgia & $506(79.8)$ & $452(78.9)$ & $54(88.5)$ & 0.06 \\
\hline Headache & $381(60.1)$ & $346(60)$ & $35(57.4)$ & 0.09 \\
\hline Nausea & $272(42.8)$ & $252(44)$ & $29(32.8)$ & 0.22 \\
\hline Abdominal pain & $235(37.1)$ & $214(37.3)$ & $21(34.4)$ & 0.07 \\
\hline Icter & $209(33)$ & $172(30.1)$ & $37(60.7)$ & $<0.00001$ \\
\hline Weakness & $115(18.9)$ & $98(17)$ & $17(27.9)$ & 0.04 \\
\hline Oliguria & $108(17)$ & $76(13.2)$ & $32(52.4)$ & 0.058 \\
\hline Anorexia & $108(17)$ & $93(16.3)$ & $15(24.6)$ & 0.04 \\
\hline Dysuria & $88(15.7)$ & $76(13.3)$ & $12(19.7)$ & 0.32 \\
\hline Vomiting & $54(8.5)$ & $46(8.1)$ & $8(13.1)$ & 0.05 \\
\hline Vertigo & $36(5.7)$ & $30(5.2)$ & $6(9)$ & 0.11 \\
\hline Cough & $36(5.7)$ & $27(4.7)$ & $9(14.8)$ & 0.05 \\
\hline Sweating & $18(2.5)$ & $14(2.4)$ & $4(6.6)$ & 0.05 \\
\hline Dyspnea & $18(2.5)$ & $12(2.1)$ & $6(9.8)$ & 0.001 \\
\hline Petechial lesion & $18(2.5)$ & $10(7.4)$ & $8(13.1)$ & 0.10 \\
\hline Tachypnea & $18(2.5)$ & $13(2.27)$ & $5(8.2)$ & 0.06 \\
\hline Hypotension & $14(2.2)$ & $10(1.7)$ & $4(6.6)$ & 0.69 \\
\hline Hemoptysis & $12(1.90)$ & 0 & $12(19.6)$ & 0.0001 \\
\hline Epistaxis & $12(1.9)$ & $3(0.5)$ & $9(14.7)$ & 0.001 \\
\hline Anuria & $10(1.8)$ & $2(0.3)$ & $8(13.1)$ & 0.002 \\
\hline Confusion & $5(0.9)$ & 0 & $5(8.2)$ & 0.001 \\
\hline Seizure & $2(0.4)$ & 0 & $2(3.3)$ & 0.05 \\
\hline Bloody diarrhea & $1(0.2)$ & 0 & $1(1.6)$ & 0.09 \\
\hline
\end{tabular}

a Dare are presented as No. (\%).

Table 2. Laboratory Findings of the Patients With Leptospirosis a,b

\begin{tabular}{|c|c|c|c|c|}
\hline Laboratory Test & Total & Uncomplicated Subjects & Complicated Subjects & PValue \\
\hline WBC, $\mu \mathbf{l}$ & $8643.93 \pm 4840.30$ & $8250.23 \pm 4377.48$ & $12329.23 \pm 7004.86$ & 0.0001 \\
\hline \multicolumn{5}{|l|}{$H b, g / d L$} \\
\hline Women & $10.98 \pm 1.86$ & $11.96 \pm 1.82$ & $10.56 \pm 1.84$ & 0.09 \\
\hline Men & $12.13 \pm 1.84$ & $13.11 \pm 2.32$ & $11.44 \pm 1.98$ & 0.07 \\
\hline Platelets, $\mu \mathbf{l}$ & $119760.12 \pm 79251$ & $121780.03 \pm 75502.42$ & $100852.45 \pm 84763.32$ & 0.03 \\
\hline $\mathrm{Na}, \mathrm{mEq} / \mathrm{L}$ & $137.43 \pm 4.40$ & $137.69 \pm 4.29$ & $135.51 \pm 4.76$ & 0.001 \\
\hline $\mathbf{K}, \mathbf{m E q} / \mathbf{L}$ & $4.20 \pm 0.55$ & $4.20 \pm 0.51$ & $4.26 \pm 0.76$ & 0.50 \\
\hline ALT, $\mathbf{U} / \mathbf{L}$ & $99.11 \pm 5.12$ & $95.05 \pm 5.06$ & $137.66 \pm 23.70$ & 0.08 \\
\hline AST, U/L & $98.00 \pm 5.78$ & $92.26 \pm 5.77$ & $152.64 \pm 25$ & 0.051 \\
\hline $\mathbf{A L P}, \mathbf{U} / \mathbf{L}$ & $187.97 \pm 105.83$ & $182.27 \pm 102.08$ & $237.11 \pm 124.36$ & 0.052 \\
\hline Bill direct, mg/dL & $3.49 \pm 0.30$ & $2.70 \pm 0.28$ & $9.55 \pm 8.72$ & 0.001 \\
\hline Bill total, mg/dL & $4.87 \pm 0.37$ & $3.89 \pm 0.35$ & $12.52 \pm 10.24$ & 0.001 \\
\hline Urea, mg/dL & $51.57 \pm 2.14$ & $45.78 \pm 39$ & $104.18 \pm 13.27$ & 0.009 \\
\hline Creatinine, mg/dL & $1.23 \pm 1.11$ & $1.16 \pm 0.89$ & $2.47 \pm 0.35$ & 0.001 \\
\hline LDH, U/L & $593.85 \pm 493.42$ & $554.93 \pm 403.16$ & $608.83 \pm 136.71$ & 0.2 \\
\hline CPK, U/L & $267.78 \pm 76.57$ & $322.53 \pm 38.99$ & $467.48 \pm 88.69$ & 0.03 \\
\hline ESR, mm/hr & $40.90 \pm 34.26$ & $34.13 \pm 30.03$ & $54.76 \pm 36.26$ & 0.01 \\
\hline
\end{tabular}

${ }^{\mathrm{a}}$ Data are presented as mean $\pm \mathrm{SD}$.

b Abbreviations: ALP: alkaline phosphatase; ALT: alanine aminotransferase; AST: aspartate aminotransferase; CPK: Creatine phosphokinase ESR: erythrocyte sedimentation rate Hb: Hemoglobin; LDH: Lactate dehydrogenase; and WBC: White blood cells. 


\section{Discussion}

The current study evaluated the clinical and laboratory characteristics of patients with leptospirosis admitted to a level 3 hospital. A total of 634 patients were studied and 61 subjects had complications. Jaundice was reported in $33 \%$ of the patients and it was significantly associated with disease severity and complications. In a similar study in France, jaundice was observed in 39\% of their patients whereas in other studies in Thailand, Brazil and Turkey, this rate was much higher $(54.5 \%, 82 \%$ and $75 \%$, respectively) (8-11). This difference could be due to the fact that most of these studies reported more severe diseases. Oliguria was observed in 108 patients (17\%) of the current study at the time of admission or thereafter, and although its incidence in many other studies was lower than that of the current observation, when comparing the two groups of subjects with and without complications, its rate was significantly higher in patients with complicated leptospirosis. Approximately $45 \%$ of the patients had platelet counts less than 100,000. Thrombocytopenia was observed in $30 \%$ and $3.47 \%$ of the patients in the studies by Orpilla Bautista and Panaligan (12) and Alian et al. (13) respectively, which was very close to the results of the current study. These laboratory findings negatively affected the disease prognosis (14). Leukocytosis was reported in $41.8 \%$ of the subjects, which was associated with mortality in the patients. While comparing the age of the patients with complicated and uncomplicated diseases it was concluded that the average age of the first group was significantly higher. This situation is described due to an increase in kidney, lung and cardiac diseases and a reduction in power of the immune system and represents a need for better management of elderly patients with leptospirosis. The average amount of creatinine in patients with and without complication was $2.47 \pm 0.35$ and $1.16 \pm 0.89$, respectively which indicated the need for careful monitoring of this factor in patients with leptospirosis to reduce the mortality and morbidity rates. Among the nine patients who died, the cause of death in seven ones was serious kidney problems and two others died due to pulmonary involvement. In the study conducted by Orpilla Bautista and Panaligan (12), the most common complication that led to death was renal involvement and all patients who died were oliguria. However, in the some other studies, the most common causes of death were pulmonary and pulmonary hemorrhage and ARDS (15-18). In the current study $22 \%$ of the patients died because of this complication. This difference is due to the fact that pulmonary involvement is usually higher in older patients (more than two-thirds of the subjects were in the age range of 20 - 60 years). For example, the average age of patients in the study by Ko et al. (15) was $53.9 \pm 15.9$; while in the current study the mean age of patients was $41.25 \pm 16.9$ years. Age, jaundice, renal and pulmonary involvement (oliguria and anuria), hypotension, leukocytosis, thrombocytopenia, hypona- tremia, elevated bilirubin, ALT, CPK and LDH and ESR, will all Increase the risk of leptospirosis complications. Renal involvement is one of the leading causes of death in such patients.

\section{Authors' Contributions}

Study concept and design: Narges Najafi, Ali Reza Davoudi, Shahriar Alian ,Fatemeh Ahangarkani, Elham Asghari; acquisition of data: Elham Asghari, Shahriar Alian, Fatemeh Ahangarkani; analysis and interpretation of data: Ali Reza Davoudi, Shahriar Alian, Fatemeh Ahangarkani; drafting of the manuscript: Narges Najafi, Ali Reza Davoudi; critical revision of the manuscript for important intellectual content: Narges Najafi, Ali Reza Davoudi, Shahriar Alian; statistical analysis: Ali Reza Davoudi; administrative, technical, and material support: Narges Najafi, Ali Reza Davoudi, Shahriar Alian ,Fatemeh Ahangarkani, Elham Asghari.

\section{Funding/Support}

This article was part of the MD thesis by Elham Asghari and this study was supported by grant no. 8984 from Vice-Chancellor for Research at Mazandaran University of Medical Sciences.

\section{References}

1. Speelman P. leptospirosis. In: Braunwald E, Fauci AS, kasper DL editors. Harrison's principles of Internal Medicine. 18th ed. New York: McGraw-Hill; 2011. pp. 988-91.

2. Faine S. leplospirosis. In: Hausler W, sussman M editors. Topley and wilson's Microbiology and Microbial Infections. 9th ed. London: Arnold; 1998. pp. 849-69.

3. Kuo HL, Lin CL, Huang CC. Reversible thick ascending limb dysfunction and aseptic meningitis syndrome: early manifestation in two leptospirosis patients. Ren Fail. 2003;25(4):639-46.

4. Southern NSW public Health unit.. Leptospirosis southern NSW public Health unit. 6. 2000;10:11-2.

5. Rathinam SR, Namperumalsamy P. Leptospirosis. Ocular Immunology and Inflammation. 1999;7(2):109-18.

6. Faraji H, Asmar M, Ebrahimipour GH, Hashemi Chalavi SA, Esfandiari B, Ziapor SP, et al. The Survey of Seroprevalence of Lleptospirosis in Mazandaran Province of Iran Using Microscopic Agglutination Test and Indirect Immunofluorescence Assay. Iran J Biol . 2009;22(4):608-18.

7. Adamson JW, Longo D. Anemia and polycythemia. In: Fauci A Braunwald E, Kasper D, Hauser S, Longo D, Jameson J, et al editors. Harrison's Principles of Internal Medicine. 17th ed. New York: McGraw Hill; 2007.

8. Abgueguen P, Delbos V, Blanvillain J, Chennebault JM, Cottin J, Fanello S, et al. Clinical aspects and prognostic factors of leptospirosis in adults. Retrospective study in France. J Infect. 2008;57(3):171-8.

9. Panaphut T, Domrongkitchaiporn S, Thinkamrop B. Prognostic factors of death in leptospirosis: a prospective cohort study in Khon Kaen, Thailand. Int J Infect Dis. 2002;6(1):52-9.

10. Spichler A, Athanazio DA, Vilaca P, Seguro A, Vinetz J, Leake JA. Comparative analysis of severe pediatric and adult leptospirosis in Sao Paulo, Brazil. Am J Trop Med Hyg. 2012;86(2):306-8.

11. Esen S, Sunbul M, Leblebicioglu H, Eroglu C, Turan D. Impact of clinical and laboratory findings on prognosis in leptospirosis. Swiss Med Wkly. 2004;134(23-24):347-52.

12. Orpilla Bautista ICL, Panaligan MM. Predictors of Mortality among Patients with Leptospirosis Admitted at the JRRMMC. Phil J Microbiol Infect Dis. 2002;3(14):145-9. 


\section{Najafi $N$ et al.}

13. Alian S, Babamahoudi F, Najafi N, Ghasemian R, Teimouri S, Shahbaznehad L. Clinical and Para clinical findings of leptospirosis in Mazandaran, June-September 2004. J Mazandaran Univ Med Sci. 2006;16(53):78-85.

14. Tangkanakul W, Tharmaphornpil P, Plikaytis BD, Bragg S, Poonsuksombat D, Choomkasien P, et al. Risk factors associated with leptospirosis in northeastern Thailand, 1998. Am J Trop Med Hyg. 2000;63(3-4):204-8.

15. Ko AI, Galvao Reis M, Ribeiro Dourado CM, Johnson W, Riley LW. Urban epidemic of severe leptospirosis in Brazil. Salvador Lepto- spirosis Study Group. Lancet. 1999;354(9181):820-5.

16. Kuriakose M, Eapen CK, Punnoose E, Koshi G. Leptospirosis--clinical spectrum and correlation with seven simple laboratory tests for early diagnosis in the Third World. Trans R Soc Trop Med Hyg. 1990;84(3):419-21

17. Davoodi A, Najafi N, Tayebi A. Pulmonary Involvement in Leptospirotic Patients. Mazandaran Univ Med Sci. 2011;21(85):69-74.

18. Baranton G, Postic D. Trends in leptospirosis epidemiology in France. Sixty-six years of passive serological surveillance from 1920 to 2003. Int J Infect Dis. 2006;10(2):162-70. 